\title{
A Treadmill Apparatus with a Computer-Assisted Functional Electrical Stimulation System by Foot Switch Controlled for Restoration of Ambulation in Stroke Patients
}

\author{
Yu-Luen Chen Walter H. Chang* May-Kuen Wong** Fuk-Tan Tung** \\ Hsiu-I Chen** Chun-Shiang Huang* Te-Son Kuo \\ Department of Electrical Engineering, National Taiwan University \\ Department of Biomedical Engineering, Chung Yuan Christian University* \\ Department of Rehabilitation, Chang Gung Memorial Hospital**
}

\begin{abstract}
A computer-assisted and foot switch controlled functional electrical stimulation (FES) system was developed to present to walking subjects real-time stimulating to their muscle during gait training. The FES was controlled by foot switch placed on the heel of unaffected foot and as a trigger to stimulate the muscles of the affected side. The purpose was to compare the effectiveness of this new developed system to a focused program of physical therapy for gait. Twelve hemiplegic patients were randomly assigned to either an experimental group $(n=6)$ treated with the new developed FES system or a control group $(n=6)$ treated with conventional physical therapy program. Gait analysis was obtained prior to and following every type of treatment. Stride length, walking velocity and functional ambulation category (FAC) were greatly increased in experimental group. A paired t-test revealed that differences in electromyography (EMG) of quadriceps and tibialis anterior muscles between patients' affected and unaffected sides were not significant after four-months training. It is concluded that a treadmill apparatus with a computer-assisted FES system controlled by foot switch is an effective tool for retraining gait in stroke patients.
\end{abstract}

Keywords :functional electrical stimulation, foot switch, hemiplegic patient, electromyography

\section{Introduction}

Body weight support and treadmill apparatus system training is widely used in various types of hemiplegic and spinal cord injured patients. The general objectives for these patients are (1) to induce or reconstruct patients' afferent sensory input of gait and (2) to avoid too much load on affected sides of patients[1-6]. The results of previous research revealed good outcomes, but the patients were receiving therapies after 2 to 3 months since stroke. The research designed a new computer-assisted foot switch controlled FES system for rehabilitation of strokes since acute. The purpose of this study was to compare the effectiveness of this system to a conventional physical therapy program for gait training in stroke patients.

\section{Materials and Methods}

Subjects

Twelve subjects (all men, age 35-50 years, 5 rightsided and 7 left-sided hemiplegia) were selected and gave their informed consent in this study. All subjects are Functional Ambulation Category (FAC) level 1 and divided into control group and experimental group randomly[7]. The control and experimental groups were treated with conventional and new computer-assisted foot switch controlled FES system, respectively. Each subject was treated 30 minutes per day, every other day, for a period of four months.

\section{Instrumentation}

The configuration of a computer-assisted FES system by foot switch controlled is shown in figure 1 . The foot switch will turn on when a pressure of approximately 150 grams is applied on the heel of unaffected foot. Than, the computer-assisted FES system was triggered by the foot switch in order to stimulate the quadriceps and tibialis anterior muscles of the affected side. A body weight support was also introduced in this study.

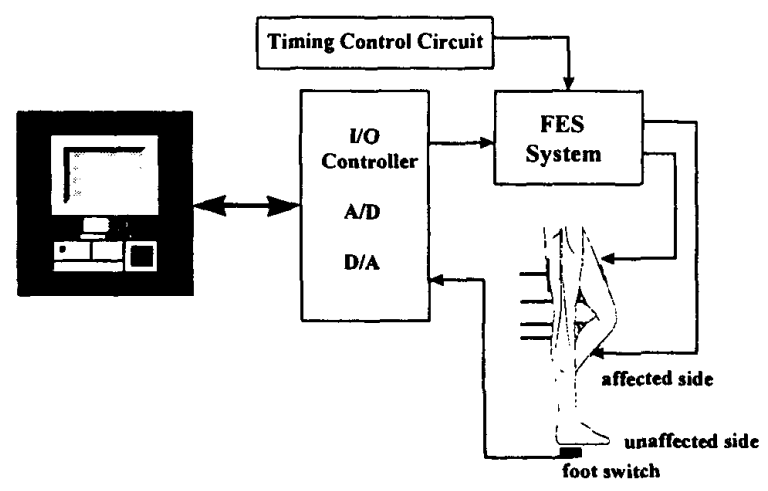

Figure.1 The developed system configuration 
A six-camera VICON system with MA-100 multichannel EMG Scanner was used to record the motion informations (stride length, walking velocity..etc.).of patients.

\section{Results}

It is clear and shown in figure. 2 and figure. 3 that the average quadriceps and tibialis anterior EMG of affected and unaffected side were getting no significant difference ( $p>0.05$ ) since the $3^{\text {nd }}$ month after treating in the experimental group. The quadriceps and tibialis anterior EMG in the control group were getting no significant difference since the $3^{\text {rd }}$ and $4^{\text {th }}$ month, respectively (figure.4 and figure.5). The increases of stride length, walking velocity and FAC were greater in the experimental group than that in the control group. It is shown in figure. 6 that FAC between the control and experimental group was significant difference since the $3^{\text {rd }}$ month.

\section{Conclusion and Discussion}

It is important to recover ambulation ability in hemiplegic patients. The new developed computerassisted foot switch controlled FES system might provided the following advantages: (1) inducing the afferent sensory input of gait pattern, (2) providing an early intervention for stroke patients.

The gait stride length, walking velocity, FAC and EMG were all improved greatly in the experimental group. These improvements may be ascribed to the computerassisted FES system controlled by foot switch.

\section{Acknowledgements}

We thank all staffs of rehabilitation engineering center of Chang Gung Memorial Hospital for clinical support.

\section{Reference}

[1] S.Hesse, C. Bertelt, A. Schaffrin, M. Malezic and K. H. Mauritz, "Restoration of gait in nonambulatory hemiparetic patients by treadmill training with partial body-weight support," Arch. Phys. Med. Rehab., vol. 75, pp. 1087-1093, 1994.

[2] M. Visintin and H. Barbeau, "The effects of parallel bars, body weight support and speed on the modulation of the locomotor pattern of spastic paretic gait. A preliminary communication," Int. Med. Society of Paraplegia, vol. 32, pp.540-553, 1994.

[3] M. Visintin and H. Barbeau, "The effects of body weight support on the locomotor pattern of spastic paretic patients," LE. Journal Canadien DES. Science Neurologiques, vol. 16, pp. 315-325, 1989.

[4] A. Wernig and S. Muller, "Laufband locomotion with body weight support improved walking in persons with severe spinal cord injuries," Int. Med. Society of Paraplegia, vol. 30, pp.229-238, 1992.

[5] S. Hesse, C. Bertelt, M.T. Jahnke, A. Schaffrin, P. Baake, M. Malezic and K.H. Mauritz, "Treadmill training with partial body weight support compared with physiotherapy in nonambulatory hemiparetic patients," Stroke, vol. 26, pp.976-981, 1995.

[6] K.E. Norman, A. Pepin, M. Ladouceur and H. Barbeau, "A treadmill apparatus and harness support for evaluation and rehabiliation of gait," Arch. Phys. Med. Rehab., vol. 76, pp. 772-778, 1995.

[7] F.M. Gollen, D.T. Wade and C.M. Bradshaw, "Mobility after stroke: reliability of measures of impairment and disability," Int. Disability study, vol. 12, pp. 6-9, 1990.

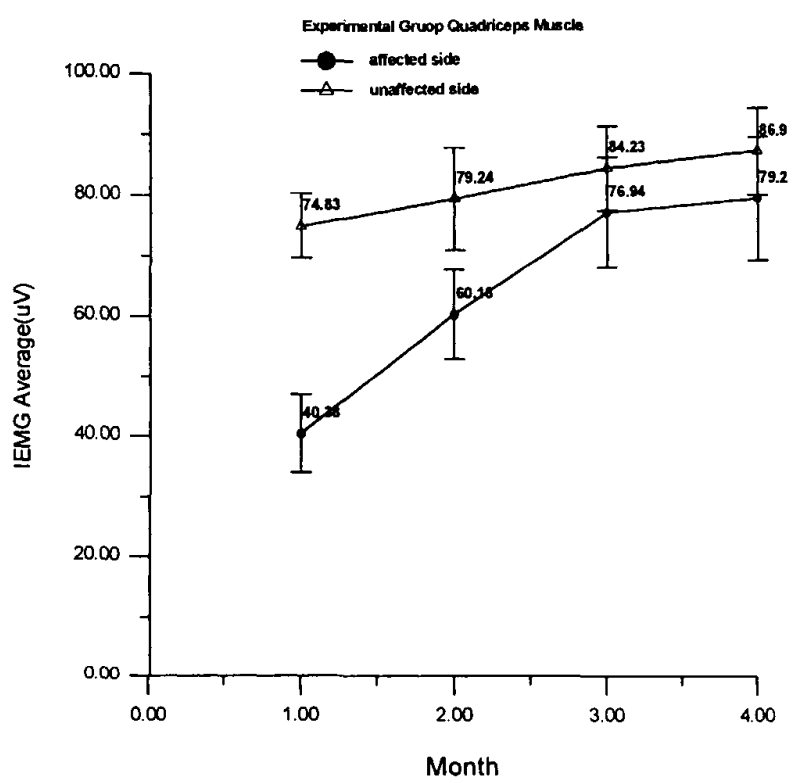

Figure.2 The results of quadriceps muscle of experimental group

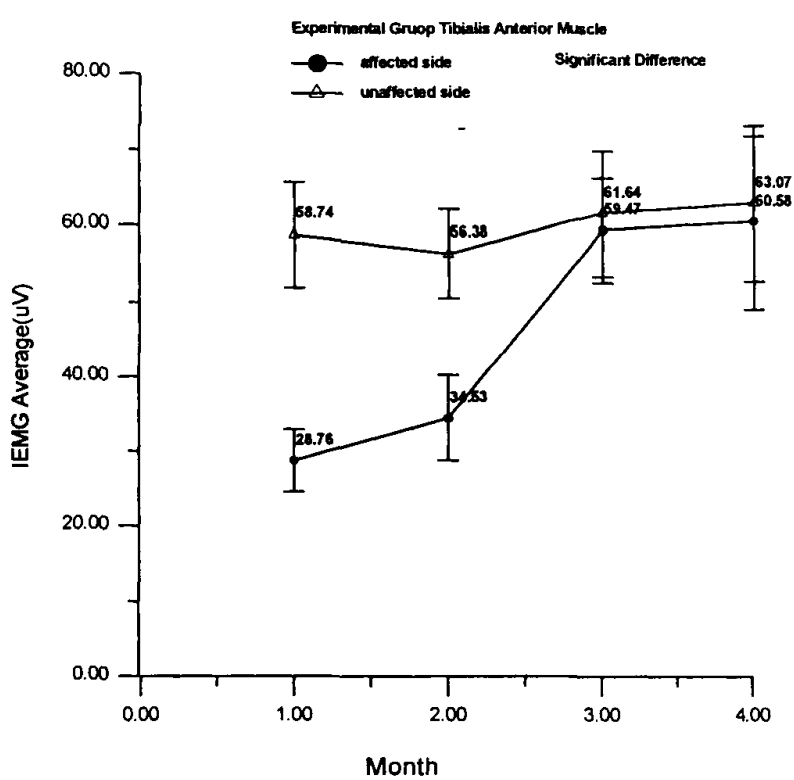


Proceedings - 19th International Conference - IEEE/EMBS Oct. 30 - Nov. 2, 1997 Chicago, IL. USA

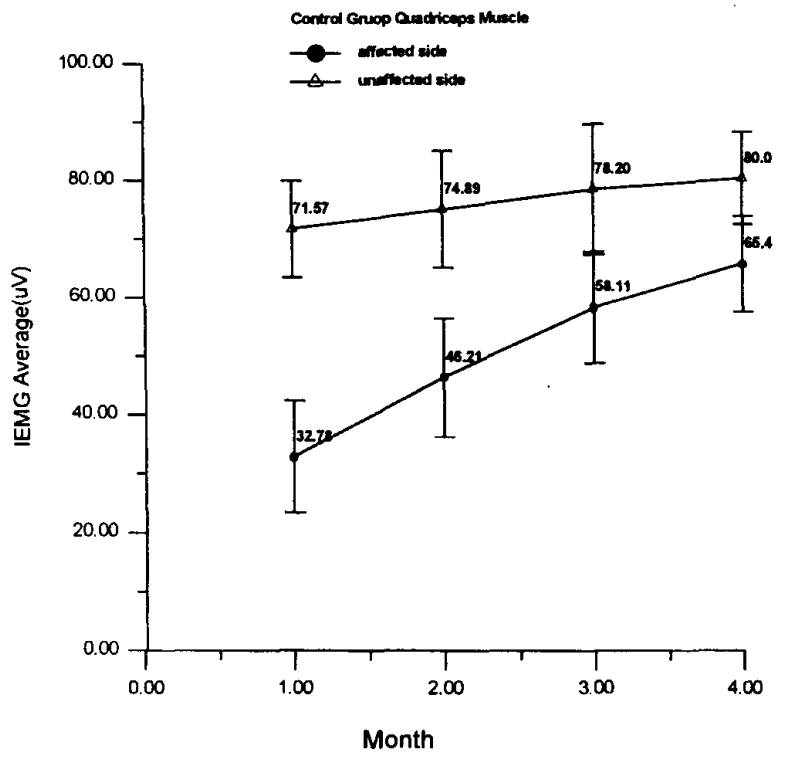

Figure.4 The results of quadriceps muscle of control group

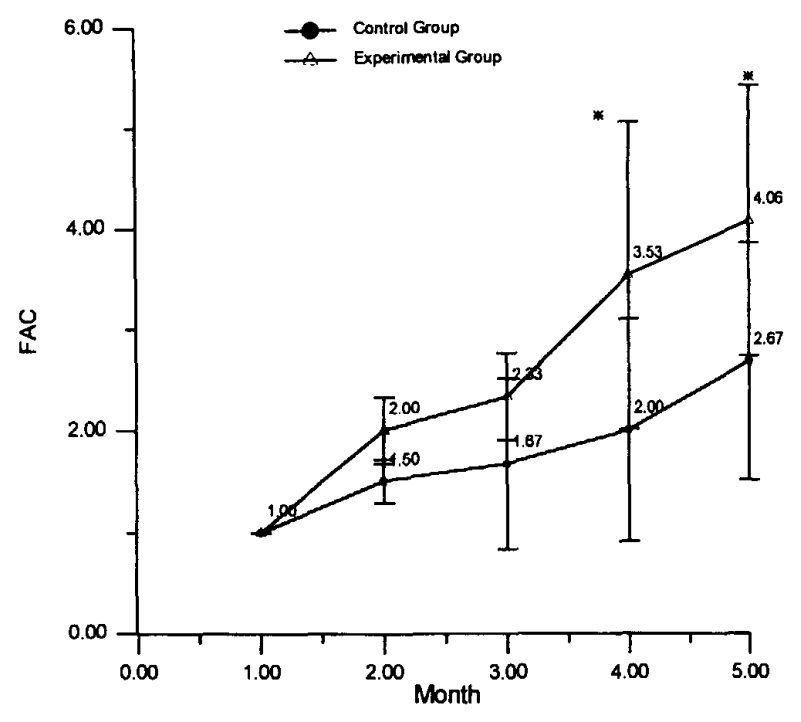

Figure. 6 The results of FAC of control group and experimental group

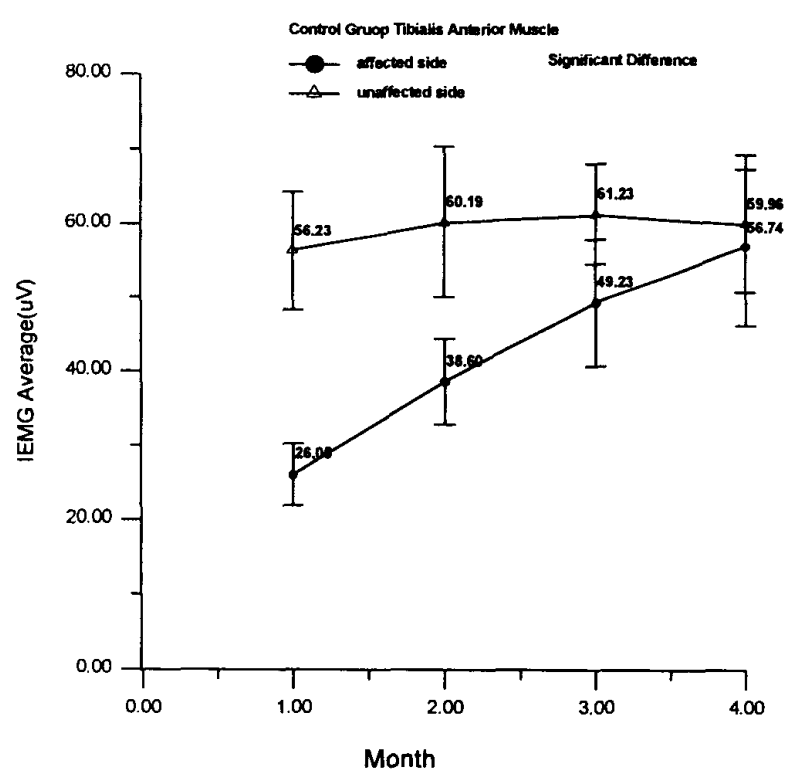

Figure.5 The results of tibialis anterior muscle of control group 